\title{
Article \\ Using Systems Thinking to Illustrate Digital Business Model Innovation
}

\author{
Erdelina Kurti ${ }^{1,2, *}$, Sadaf Salavati ${ }^{1,2}$ (D) and Anita Mirijamdotter ${ }^{1,2}$ (D) \\ 1 Department of Informatics, Faculty of Technology, Linnaeus University, 35195 Växjö, Sweden; \\ sadaf.salavati@lnu.se (S.S.); anita.mirijamdotter@lnu.se (A.M.) \\ 2 Linnaeus University Systems Community, Linnaeus University, 35195 Växjö, Sweden \\ * Correspondence: erdelina.kurti@lnu.se
}

Citation: Kurti, E.; Salavati, S. Mirijamdotter, A. Using Systems Thinking to Illustrate Digital Business Model Innovation. Systems 2021, 9, 86. https://doi.org/10.3390/ systems 9040086

Academic Editors: Anders Hansen Henten and Iwona Windekilde

Received: 29 October 2021

Accepted: 1 December 2021

Published: 3 December 2021

Publisher's Note: MDPI stays neutral with regard to jurisdictional claims in published maps and institutional affiliations.

Copyright: (C) 2021 by the authors. Licensee MDPI, Basel, Switzerland. This article is an open access article distributed under the terms and conditions of the Creative Commons Attribution (CC BY) license (https:// creativecommons.org/licenses/by/ $4.0 /)$.

\begin{abstract}
Digital business model innovation is discussed by bringing together systemic innovation and digital innovation. Applying the Rich Picture technique, the complexity transpiring in the digital innovation of the business models is illustrated. Further, a real world example is presented and discussed in relation to systemic innovation and digital innovation. This study further contributes by shedding light on the added complexity brought by digital innovation but also the need for a combined and mixed systems thinking approach.
\end{abstract}

Keywords: digital business model innovation; digital innovation; systems thinking; Rich Picture; complexity; Netflix

\section{Introduction}

Advancement of digital technologies has spawned profound innovation opportunities. This impact is observed across a number of industries, which are being reshaped by digital technologies. In order to strive in the ever changing landscape, organizations need to embark on continuous digital innovation efforts. Digital innovation is defined as "the process of combining digital and physical components to create novel devices, services or business models, bundling them to constitute and enable market offerings, and embedding them in wider sociotechnical environments to enable their diffusion, operation and use" [1] (p. 433). Systemic implications and complexity stemming from digital innovation have become key concerns for both research and practice.

In this paper we focus on digital business model innovation as an instance of systemic innovation [2] and digital innovation [3]. According to Amit and Zott [4] (p. 4) "a business model is about 'how to do business', and business model innovation is about 'how to do business in new ways'". Utilization of holistic thinking has been voiced as a powerful approach for business model innovation, by both strategic management literature [5] and, recently, systems thinking literature (e.g., [2]). In the same line of reasoning, we also argue for the potential of systems thinking to address digital business model innovation. Systems thinking is a transdisciplinary perspective which enables complex and multidimensional environmental, social, and organizational real world situations to unfold and be tackled. Systems thinking is a holistic approach which provides a language and a set of tools tackling underlying patterns and structures, mental models, and relationships (e.g., [6-13]). It can be viewed as a practical application of various systems ideas [14]. Despite the appreciation of systems thinking for business model innovation, previous literature (e.g., [15-17]) mostly assumes the hard systems approach and considers business models as systems. However, the application of systems thinking to business model innovation remains mainly blackboxed [18].

We aim to contribute to a contemporary phenomenon of our society-digitalization. By using the Rich Picture technique (e.g., [9]), a systems thinking tool, we illustrate relationships, entities, and underlying structures of the dynamic multifaceted complexity of 
digital business model innovation. Further, this is an attempt to bring together systemic innovation and digital innovation through the notion of digital business model innovation.

In what follows, we first provide a brief summary of business models and digital business model innovation. We then proceed with a brief outline of related work, which brings together business models and systems thinking. This is followed by an illustration and description of the complex situation of Digital Business Model Innovation along with a practical case example. The paper is finalized with a discussion and concluding remarks on future prospects.

\section{Business Models}

The business model concept elevated with the emergence of the Internet, which gave rise to new forms of business practices [19]. Since then, the concept has proliferated and earned a prominence in both academia and practice [20]. A detailed review of the business model body of research, its evolution, classification of the literature, and its dynamics is out of the scope of this paper, since the scholarly work contains many such reviews already (for thorough reviews, see, e.g., [20-24]).

Despite the increased importance, there is no consensual definition on business models [22], and scholarly work is quite dispersed [20]. Massa et al. [22] classify the burgeoning literature into three main strands, which provide different interpretations of business models. The first strand considers business models as properties of real organizations, where the business model depicts the organization's activity system, which explains how the business is conducted. The second strand interprets business models through a cognitive prism. It specifically views business models as cognitive representations [25], held in managers' mental models. This cognitive framing, often recognized as "dominant logic" [26], shapes the decision making and subsequent innovation efforts. It is recognized to be a main barrier to spot market opportunities, shape the innovation journey [27], and yield value from digitalization. The third perspective according to Massa et al. [22] interprets business models as simplified versions of real systems, represented as formal conceptualization of activities.

Nevertheless, among the scattered work across disciplines [20], there is a noted consensus on two points: firstly, the core of business model notion is the value creation and capture; and secondly, a business model represents a boundary spanning concept, hence demanding a holistic scrutiny $[28,29]$.

In the work of Amit and Zott [19], a business model emerges as an analytical concept derived from a thorough scrutinization of traditional theories of value creation, value chain [30], resource based view [31], Schumpeterian innovation [32], strategic networks [33], and transaction cost economics [34]. In their work, Amit and Zott [19] conclude that the digital realm challenges the conventional understanding of value creation, and the traditional theories of value creation cannot fully grasp digitalization and its implications. These theories alone can only provide partial explanations; therefore, Amit and Zott [19] propose the business model as an aggregated concept to account for digitalization and its implications. Whereas their initial work focused on transactions, the latter work assumes an activity system perspective [5,28]. Nonetheless, as Zott and Amit [28] (p. 219) argue, these two perspectives do not cancel each other out; instead they are "two sides of the same coin", because the link between activities is enabled through transaction mechanisms [28]. The activity system perspective as presented by Zott and Amit [28] is a comprehensive way of understanding and explaining the value creation and delivery, by depicting business model as a purposeful assemblage of interconnected and interdependent activities performed by the organization, but also other actors in the ecosystem. Activity is defined as "as the engagement of human, physical, and/or capital resources of any party to the business model (the focal firm, end customers, vendors, etc.) to serve a specific purpose toward the fulfillment of the overall objective" [28] (p. 217). Specifically, they define the business model as depicting "the content, structure, and governance of transactions designed so as to create value through the exploitation of business opportunities" [28] (p. 511). The 
three elements that characterize the business model are content, structure, and governance. Content, or the "what" of business models, describes the activities that are conducted in order to deliver value propositions to satisfy a market need. Structure, or the "how" element of business models, refers to the way the activities are connected, their sequence, as well as their contribution to the business model in terms of whether they have a primary or supporting character. Governance, or the "who", describes the actors responsible for performing the activities and underlying control mechanisms [28].

Amit and Zott [19] and Zott and Amit [5,28] identify and further elaborate four main drivers of value creation, which organizations activate alone or in combination. These drivers revolve around which business models could be designed, include novelty, lock-in, complementarities, and efficiency. Novelty refers to novel configurations of activities, actors, and relationships. Efficiency refers to the way organizations configure their activity systems to gain greater efficiency through the reduction of costs. Complementarities according to Zott and Amit [28] refer to the creation of synergies between offerings, activities, actors, and/or resources, which would result in greater value than each of them separately. The lock-in theme is argued to be present when companies, through activating mechanisms such as switching costs or incentives, prevent customers from drifting away to other competitors. Moreover, Amit and Zott [19] argue that value drivers are not mutually exclusive. One or several drivers can be present in the very same business model, and often they solidify each other [19]. This becomes more evident especially in the volatile digital context.

Business models are dynamic [35], especially in the light of constant and ongoing digital evolution. Therefore, digital innovation of business models becomes an imperative for survival in the ever changing ecosystem.

\section{Digital Business Model Innovation}

As mentioned above, the concept of the business model gained considerable popularity in both academia and practice seemingly as a result of advancement of digital technologies [20]. Hence, the business model concept is intrinsically related to digitalization. Digital technologies themselves do not contribute to value creation and capture. Instead they must be leveraged and exploited in novel ways which yield value creation and capture, that is, through business models, as a concept which bridges the technological aspects with economic aspects such as value creation and capture [36].

Digital business model innovation represents an instance of digital innovation, along with product and process innovation [3]. Fichman et al. [3] (p. 330) define digital innovation as "a product, process or business model that is perceived as new, requires some significant changes on the part of adopters, and is embodied in or enabled by IT". Further, according to the authors, digital business model innovation refers to novel forms of value creation and capture enabled by digital technologies. In other words, digital business model innovation refers to the ways organizations harness the potential of digital technologies to create and capture value in a novel way, not only for themselves but also other actors in the ecosystem. Following Zott and Amit [5] and Snihur and Zott [37], we perceive digital innovation of business models as the changes in the content (introduction of new activities, modification of existing ones, and/or elimination of some activities), structure (novel ways of activity linkages), and/or governance (introduction of new actors who conduct activities), all enabled by digital technologies. In this paper, digital business model innovation does not solely imply a full transition or transformation to digital, but also it includes a hybrid model, where the non-digital way of doing business coexists with the digital.

There is a consensus that business model innovation is intrinsically complex and difficult (e.g., [27,37]). The difficulty emerges due to the high interdependency between the elements of the business model resulting in the innovation of the whole activity system [5]. However, what makes digital innovation of business models particularly complex is specific attributes such as the decoupling between form and function and content from medium, blurred boundaries, different dynamics, and value co-creation (e.g., [38-40]). 
These attributes inherent in digital technologies represent the cornerstone for digital innovation [38] and digital business model innovation, respectively. Digital innovation is regarded as a "new innovation regime" [40], distinct from other forms of innovations [41]. The properties of digital technologies afford a large degree of flexibility and make digital innovation a process and an outcome with no clear defined boundaries and agency of innovation [41]. Digital innovation of business models entails an entirely different dynamic. The ubiquitous nature of digital technologies eliminates barriers, hence affording the entrance of new actors in incumbent contexts [38]. Digital innovation challenges the traditional notion of value creation and instead assumes that value is co-created by "aggregating recombinant technology components by interacting with diverse resources and often across firm boundaries" [39] (p. 488). This results in blurred industry boundaries and gives rise to a new competitive dynamics [38].

Whereas digital innovation presents ample opportunities, it also creates challenges and complexities particularly for incumbent organizations [42]. Digital innovation breaks with the traditional assumptions shaped by the industrial innovation logic [40]. Oftentimes digital innovation demands incumbents to maintain the existing practices and the way of doing business alongside the new digital logic, which gives rise to tensions and complexity [42].

\section{Business Models and Systems Thinking}

This section provides a summary of the related research on the relationships between business models and systems thinking. The review of the literature uncovers two interrelated strands: one which focuses and views business models as systems, and another which centers on the potential of systems thinking to address business model dynamics.

\subsection{Business Model as a System}

There is an overall consensus that business models denote a system. A variety of definitions make inferences to the business model representing a system (e.g., [19,25,43]). For example, according to Zott and Amit [28] (p. 216) business model represents "a system of interdependent activities that transcends the focal firm and spans its boundaries". So according to them, the business model is a system composed of interrelated activities centered and conducted by the focal organization but also includes other activities performed by other actors outside the firm and even industry boundaries. As evident from the definition, a business model implies a system-level approach [37] to explaining how firms do business [28]. Similarly, Martins et al. [25] (p. 99) claim that the business model depicts "the designed system of activities through which a firm creates and captures value". These definitions, along with others, in addition to making inferences to the term system, do not make specific associations to the systems thinking literature. In a closer look, these definitions resemble the definition of a system by Meadows [8], who defines a system as not "just any old collection of things. A system is an interconnected set of elements that is coherently organized in a way that achieves something" [8] (p. 11). However, there are also studies that make explicit relations between business models and systems thinking. For example, Berglund and Sandström [43] considers business models as open systems, not having an isolated existence, but being a part of and dependent upon a larger ecosystem. Massa et al. [16] go further, claiming that business models represent "complex systems" According to them, a complex system is "a system comprising a large number of parts characterized by non-linear interdependencies, together creating a whole that is more than the mere sum of its parts" [16] (p. 59).

We concur with the view that the business model represents a complex system. However, that is not the core focus of this paper. This perspective represents the static view of business models [35], and according to Midgley and Lindhult [2], the early stages of systems sciences, which regard systems as complex real world phenomena to be objectively captured. Whereas it would be interesting to extend this view further, that is a recommendation for future research. In this paper, we instead focus on the dynamic perspective of 
business models [35], specifically on the value and potential of systems thinking to tackle the complexity that transpires in digital innovation.

\subsection{Business Model Innovation from a Systems Perspective}

In addition to just merely viewing business models as systems, several scholars have applied systems thinking in the business model area (e.g., $[15,17,44,45])$. Halecker and Hartmann [44] argue that the existing body of research fails to provide insight into how systems thinking can be applied to business model innovation. Nevertheless, some later papers have shed some light in that regard. This section provides an overview of a number of scholarly works on business model innovation from a systems perspective.

Velu [15] draws parallels between general systems theory [46] and business models. In that light, Velu [15] advocates systems thinking as a suitable perspective for understanding the dynamics of business models. He provides a conceptual systems thinking framework based on Distinctions, Systems, Relationships, and Perspectives (DSRP) by Cabrera and Cabrera [11] for overcoming cognitive barriers. This type of barrier is considered as one of the main challenges to business model innovation [27]. Cavallo et al. [17] advocate the system dynamics for addressing the evolution of business model innovation. Through the "Causal Loop Diagram" (CLD), the authors map the interrelationships between the different elements of the business model in the innovation process. In neither of these scholarly works we can identify how systems thinking approaches have been carried out and applied to business models.

In contrast to the above mentioned studies, Hindle and Vidgen [47] embrace a soft systems approach to business model innovation. They combine Soft Systems Methodology [9] with business model canvas [48] and propose the Business Analytics Methodology as a systematic tool for modelling and facilitating business model innovation. Similarly, Pereira et al. [45] utilized Soft Systems Methodology (SSM) in combination with business model canvas [48]. The authors applied the seven step model of SSM as a pre-stage to the business model canvas modelling, which was further developed to the SSM Learning Cycle (e.g., [49]). We see a limitation in applying the seven step model, as it is not iterative and not as "soft" as the SSM Learning Cycle. Another systems thinking approach addressing Business Model Innovation is, for instance, the work of Halecker and Hartmann [44], who propose the Integrated Systems Approach as an overarching model with the potential of including hard and soft systems approaches. However, the study does not clearly unfold how the combination of the hard and soft approaches comes into play. Monat et al. [18] discuss the challenges of the practical application of systems thinking. They attribute the failures of several businesses as a lack of adopting systems thinking. In a recent study, Midgley and Lindhult [2] focus on systemic innovation from a systems perspective. They classify systemic innovation into five categories: (1) technologically driven innovation, (2) policy and governance development to support innovation, (3) transition to a sustainable society aiming for more desirable patterns of production and consumption, (4) collaboration between multiple and interdependent actors embedded in an ecosystem, and (5) thinking in terms of systems. Thus, Midgley and Lindhult [2] argue for systems thinking as a fruitful theoretical and methodological approach to enhance the understanding of business model innovation.

Previous studies on the intersection of business models and systems thinking have advocated systems thinking as a promising approach to business model innovation. However, studies on the complexity emerging from the digital innovation of business models are scarce, and there is further major potential in addressing how systems thinking can be applied to address digital business model innovation.

\section{Illustration of Digital Business Model Innovation}

Up to this point we have presented the literature on the complex nature of business models, and the additional complexity emerging from digital innovation. Gharajedaghi [10] states "We see the world as increasingly more complex and chaotic as we use inadequate 
concepts to explain it. When we understand something, we no longer see it as chaotic or complex" (p. 24). He further argues that a holistic language, a language of systems, enables the chaos to unfold and the complexity to be understood. In the same vein, Cabrera [50] argues that systems thinking makes it possible to see the complex reality of the natural real world, that is, to look deeper and uncover patterns, systems structures, and mental models.

For this paper we have chosen the Rich Picture technique of the Soft Systems Methodology. The Rich Picture technique offers a non-linear approach to show relationships, entities, structures, and viewpoints (e.g., [9]) and hence provides a more comprehensive picture of the phenomenon. Figure 1 illustrates a generic overview of business models and digital innovation, i.e., digital business model innovation. The Rich Picture is then explained using theories of business model and digital innovation. The Rich Picture will first be explained from the business model perspective and thereafter expanded with the digital innovation dimension, hence providing an overview of the complex and dynamic nature of digital business model innovation.

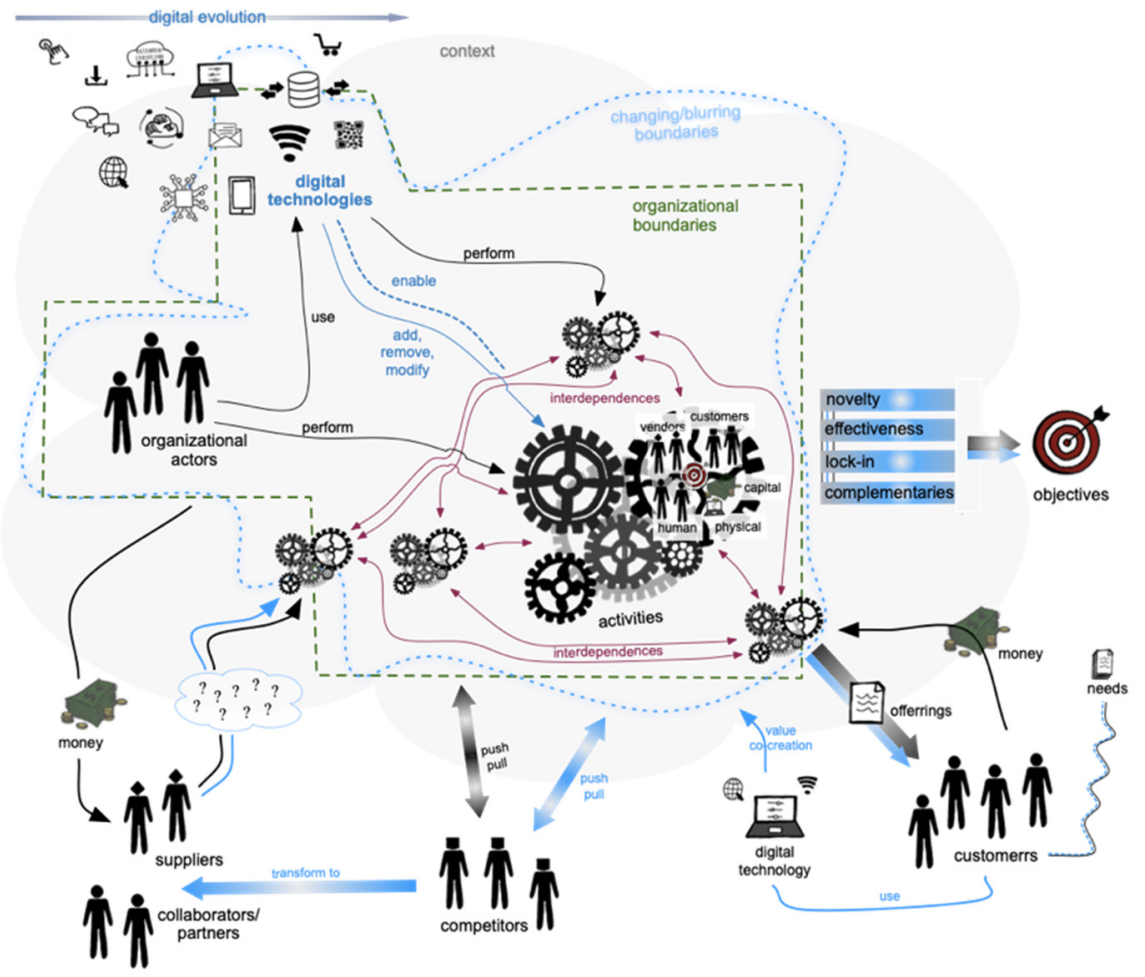

Figure 1. Rich Picture of Digital Business Model Innovation.

This section is then finalized with a presentation of a practical case example.

\subsection{Generic Rich Picture of Digital Business Model Innovation}

In the Rich Picture in Figure 1, the process and outcome of digital innovation is illustrated with blue colored lines. The green dashed line illustrates the traditional boundaries (non digital) of the organization. The black colored lines illustrate the relationships, and the maroon lines illustrate interdependencies (i.e., the structure).

Zott and Amit [28] define a business model as a purposeful activity system of interdependent and interrelated activities, performed by the organization and other actors in the ecosystem in order to produce an offering to fulfill a market need. In the Rich Picture above, this is illustrated as follows: The grouping of cogwheels in the center of the picture illustrates the activities (i.e., the content). Each activity is interdependent and interrelated to other activities, as illustrated with two sided maroon colored pointing arrows. The activities, as described by Zott and Amit [28], consist of several sub activities (each individual cogwheel should be understood as a single activity) where an activity has an objective (red 
and white bullseye in the middle of the larger cogwheel), humans, vendors, customers (illustrated as stick figures), capital, and/or physical resources illustrated in the lower right side of the large cogwheel in the middle. Illustrated as stick figures with round heads at the middle left side of the figure, the organizational actors perform the core activities. However, some activities could be performed by other actors outside the organization boundaries such as suppliers (stick figures with diamond heads, a cloud with question marks illustrated in the middle-lower left side and the customers in the middle-lower right side). The offering (products and/or services) is illustrated in the lower right side of the figure and is also an integral part of the gray-blue boxes in the middle right side of the figure. The gray-blue boxes are part of the objective of the organization's business model (illustrated as a red-white bullseye) and as part of that fulfilling a market need [28], exemplified by the needs of the customer illustrated in the lower right side of the figure.

The four sources of value creation, i.e., novelty, effectiveness, lock-in, and complementarities [28] are represented as grey-blue boxes in the middle right side of the figure). The dark gray color illustrates the value creation in a non-digital context, while the blue color represents digital technologies and digital driven innovations. The second trait of business models is its boundary spanning nature (e.g., [28]), illustrated in the lower part of the figure, divided into three parts. First, in the left corner, the suppliers are illustrated providing services, tools, raw material, etc. (illustrated as a cloud with question marks). Second, competition is illustrated in the middle, and third, the customers, who have different needs due to digitalization, are illustrated with a blue dashed line at the right end of the figure. The organization aims to fulfill the customers' needs by providing offerings (illustrated in bold arrows in the middle of the lower right corner) in return for receiving financial value (represented as money).

Digital technologies, as the main enablers of digital innovation [38,39], are illustrated in the top left corner together with the digital evolution illustrated as a moving forward arrow. The digital technologies (illustrated inside and outside of the organization boundaries) challenge the way value is created and captured [28], and this is illustrated throughout the picture in blue color lines, arrows, and boxes/shadows. Digital technologies affect the three elements of the business model [28]: content or the what, which entails the activities conducted (illustrated with a solid blue arrow in the middle of the figure), the structure or the how, which represents the way these activities are connected and their sequence (illustrated as a dashed blue line in the middle of the figure) and governance, which refers to who perform the activities (illustrated with a solid black arrow in the middle of the figure), where these actors include internal actors, the technology, and/or actors outside organizational and even industrial boundaries.

As illustrated with the dashed blue line, digitalization has blurred and even changed organizational boundaries. Examples of this impact include the blurred and changing roles and relationships of actors within the ecosystem; customers can become co-creators of value (illustrated in the right side corner of the figure); or competitors, who become collaborators, hence having multiple roles (illustrated as a bold blue arrow in the lower middle and left side of the figure).

A final highly important aspect to consider is the context in which the organization is embedded. The context is represented by a large cloud in the Rich Picture. It should be noted that due to digitalization, the organizational boundaries can end up outside of the incumbent context, and other actors who reside outside the organization might be within or outside the specific context.

\subsection{Digital Business Model Innovation in Practice}

There are several case examples of different companies who struggled or managed to leverage the potential of digitalization in order to create unprecedented innovations and value. In this light, drawing on previous studies, we present an example of digital business model innovation. The case example is Netflix, which is a global company in the digital media landscape. It is impossible in this section to include detailed aspects of business 
models in terms of content, governance, and structure. Therefore, this is not intended to be an exhaustive depiction, but a mere generic overview.

Netflix has been the subject of an array of scholarly work (e.g., [51-54]) as a case example of a successful business model innovation but also as a success story of an ambidextrous organization [54].

Netflix is characterized by three major business model innovation leaps: DVD rental service, content streaming, and production of original content [52,54]. The business model innovation of Netflix had far-reaching implications for the video rental market first, resulting in the bankruptcy of other competitor companies, e.g., Blockbuster. Later on, Netflix managed to enter new markets (film industry) and competed with Hollywood studios (e.g., Warner Brothers, Paramount Pictures, Universal Pictures) [53] and also was nominated and won several awards.

Snihur and Zott [37] illustrate the Netflix business model in the end of 1990. Netflix utilized novel technologies at that time, namely DVDs and the Internet, for delivering its offerings, which were movies on DVD. As Snihur and Zott [37] describe, Netflix introduced novel activities such as transactions through the website and mailing of DVDs, in addition to internal technology optimization related activities. To enable this, they partnered with several actors such as movie studios and DVD producers but also with a shipping company (U.S. Postal Services). Moreover, Netflix innovated the structure of the business model, where customers performed order transactions online and received the movies in their homes instead of picking them up at physical video stores [37] (p. 556). For a fixed monthly subscription, customers could rent unlimited movies [51].

A few years later, Netflix shifted the focus of the business to online streaming and content production [54]. This innovation was characterized by changes in all three elements of the business model: content, governance, and structure. Netflix offers an extensive, on-demand, ad-free library of content, through a rather simple and efficient subscription model [52]. In terms of the business model content, Netflix's activity system is composed of a multitude of interrelated activities ranging from provision and delivery of DVDs, to content acquisition; licensing, streaming, and production and commissioning of own original content; various local language content productions [53]; activities related to future video game offerings; and data analytics to understand and predict customer behavior in order to improve and provide personalized experience, marketing, and recommendations [51,52]. The majority of activities is conducted internally but Netflix also collaborates closely and relies on several other actors. To name a few, Netflix collaborates closely with content providers, producers, and creators. Moreover, as Fagerjord and Kueng [52] explain, distribution of the content is dependent and enabled by content delivery networks (CDN) and technological infrastructures, e.g., Internet and Mobile service providers. Amazon Web Services enable the international billing infrastructure, and Netflix has delegated data processing tasks to them [52]. Further, as they explain, all these various actors who partake in the business model collect data from one another. Technology enables almost all activities, delivery of services, and the data analytics, which is the cornerstone of Netflix business model [52]. Other collaborators include smart TV companies, the gaming industry, and local partners for local language productions. Customers use different technological devices to view the content. They have control of the selection of the movies, when they want to watch them, and through which means. They watch them in the convenience of their own home [53].

A brief analysis shows that Netflix creates value by drawing on four drivers of value creation as presented by Zott and Amit [28] and Zott and Amit [5]. Similarly, some mechanisms activate several of the drivers. Netflix creates value for its users by providing original unique content (novelty), which they cannot find in other platforms, at least not with ease. The original content also serves as a lock-in mechanism. Netflix also provides a user-friendly interface, with easy selection possibility, and so-called "binge watching" [52], which refers to access to several episodes and/or entire seasons of TV series at one time [52]. Moreover, it provides an uninterrupted possibility of content consumption regardless of the 
devices. All these factors serve as lock-in mechanisms. Efficiency is another activated source of value creation. Netflix provides an efficient, inexpensive way to watch movies [52], with convenient and straightforward pricing, and the possibility of offline downloading [55]. Complementarities are another noticed value driver. Complementaries are evident in the bundling of various content (enormous library), distribution channels (desktop, tablet, mobile, apps, film festivals), and users, such as allowing several members of the same household to have access to different content. The latter could also be perceived as a lock-in mechanism.

The success of Netflix is attributed to the long-term innovative vision of the management, who were able to see beyond the market needs [54,56]. Most importantly, however, their success did not hinder Netflix to see beyond. Management of Netflix did not hesitate to disrupt their own legacy business model, which was still successful. In an interview by Jaworski [56], a former manager of Netflix states "If you're obsessed about upsetting your legacy business, you're screwed to begin with" (p. 187). This potential to use digital technologies in a novel manner, the capacity for managing ambidexterity, and the continuous start-up mindset [54] enabled Netflix to move from a retailer and enter another market space, that of the film studios.

\section{Discussion}

In this paper we conceptualize and illustrate digital business model innovation as an instance of systemic innovation [2] and digital innovation [3,5]. This paper brings together these two strands under the notion of digital business model innovation. Whereas in Fichman et al. [3] this representation of digital business models is obvious in the definition itself, in Midgley and Lindhult's [2] work, we see digital business models falling in at least four of their categorizations of systemic innovation, namely technologically driven innovation, transition to a sustainable society aiming for more desirable patterns of production and consumption, collaboration between multiple and interdependent actors embedded in an ecosystem, and thinking in terms of systems. The case used in this paper, although used to illustrate the digital business model innovation, also sheds light on the systemic features of the digital business model innovation of Netflix.

We argue that the digital business model innovation of Netflix was technologically driven. In the end of the 1990s, Netflix used the technology at that time (DVD, Internet) in an innovative manner which resulted in changes of the movie rental industry. The technology driven innovation also led to societal changes, resulting in the changing behavior and norms of customers. Netflix reinvented the way movies are delivered and consumed. The implication is that Netflix significantly influenced the needs and behavior of customers. Rather than buying and owning products, customers now have access to a large bundle of content and instead consume content on demand. These changes can also be seen in relation to other external actors. Netflix's business model innovation was enabled by a collaboration between several actors. Each business model innovation leap introduced new actors with distinct capabilities, such as, first, the U.S. Postal Service, and later, Amazon Web services, Internet and mobile providers, TV companies, and local partners, among others. Digital technologies were a crucial actor in every innovation leap of the Netflix activity system. The fifth categorization of Midgley and Lindhult [2], that is, thinking in terms of systems, is discussed in relation to the characteristics of digital technologies which have given rise to these innovations.

In this study, the business model is conceptualized as a potential of using technologies to create value [36], not only for the individual company but also for other actors in the ecosystem. Features of digital technologies, respectively, the decoupling of the content from the medium, was the main enabler of innovations in Netflix. The dematerialization of information made these innovations possible; however, it was the ability of Netflix to reap the potential of digitization which made them become a leader and disrupt an incumbent sector. The success of Netflix is attributed to the long-term innovative vision of the management and their ability to disrupt their existing and rather successful business model. This 
was for instance highlighted in Jaworski [56]. In the case of Netflix, although the sources we have drawn upon do not refer to systems thinking, we observe traces of systems thinking into Netflix innovation efforts. In addition to the technology, Netflix managed to fully align other factors and actors into its digitalization journey, which transcended the boundaries of the organization and disrupted an established market. This feature of systemic innovation resonates with the cognitive research strand on business models (e.g., [22]); however, it moves beyond the managers' mental models in the innovation process to the whole of the actors partaking in the innovation.

In line with Midgley and Lindhult [2] we see that the last category also influences all other categories of systemic innovation. In the case of Netflix this is observed in the changes of managerial mindset, customer behavior, competition, and collaboration, all due to digital technologies and digitalization.

Further, as a result of digitalization, boundaries are transcended but also fluid [41] and hence more complex. Digital innovation affects all elements of business models and thereby adds levels and additional dimensions to the complex dynamic nature of business models. With the Rich Picture we have captured and illustrated this complexity. This systems thinking technique has provided us a systems language to depict the activities, the relationships, the offerings, and the co-creation of value, as well as the actors and their shifting roles. The Rich Picture in this paper brings together business models and digital innovation in an emerging overview within the larger business model context.

Nevertheless, what we present is generic and covers the main components of digital innovation of business models. It is challenging and even impossible to cover all complexity and multidimensionality of digital business model innovation as a real world phenomena. Therefore, it is crucial to acknowledge unique features such as the organizational context area and also the aim and the purpose of a project focusing on digital business model innovation.

Further, it is important to have in mind that the case we have presented was established in the breaking point of the digital era and represents a successful case of digital business model innovation and ambidexterity. Traditional incumbent organizations from different sectors (e.g., law, newspapers, car industry, healthcare) face additional complexities in their digital business model innovation journey.

The systems thinking perspective, which has been voiced by several other authors (e.g., [16-18]), has immense potential to address and tackle the complexity of digital business model innovation. Furthermore, due to the dynamic multifaceted complexity, we see the need for several systems methodologies to cover different dimensions of the complexity and hence reaching a more holistic understanding of the phenomena.

\section{Concluding Remarks}

In this paper, through the review of previous literature, the use of Rich Picture, and presentation of Netflix, we depict the emerging complexity from digital innovation. We show that each digital innovation leap brings about changes in business models' constellations, hence adding several levels and different dimensions to the complexity. Further, the outcome of this study shows that the complexity is salient across several aspects, such as offering, activities, relationships between the activities and actors, and their roles. In order to explain, explore, and tackle the dynamic complex situation of the digital business model innovation, a more comprehensive approach is needed. We therefore suggest a combined and mixed systems thinking approach for addressing digital business model innovation (e.g., $[57,58])$. Applying such an approach allows systems methodologies to be combined with methods with different strengths and focuses, hence gaining a more holistic understanding of digital business model innovation. In line with Midgley and Lindhult [2], we advocate for the potential of a combined and mixed systems thinking approach. We strongly encourage such an application in future research frontiers related to digital innovation. 
Author Contributions: For this research article, E.K. and S.S. are the main authors and researchers. E.K. and S.S. wrote the original draft. A.M. contributed in the commenting and the revision process. All authors have read and agreed to the published version of the manuscript.

Funding: This research was funded by Linnaeus Knowledge Environment Digital Transformations and Knowledge Foundation, grant number 20190256.

Institutional Review Board Statement: Not applicable.

Data Availability Statement: Not applicable.

Conflicts of Interest: The authors declare no conflict of interest.

\section{References}

1. Skog, D.A.; Wimelius, H.; Sandberg, J. Digital Disruption. Bus. Inf. Syst. Eng. 2018, 60, 431-437. [CrossRef]

2. Midgley., G.; Lindhult, E. A systems perspective on systemic innovation. Syst. Res. Behav. Sci. 2021, 38, 635-670. [CrossRef]

3. Fichman, R.G.; Dos Santos, B.L.; Zheng, Z.E. Digital innovation as a fundamental and powerful concept in the information systems curriculum. MIS Q. 2014, 38, 329-343. [CrossRef]

4. Amit, R.; Zott, C. Business Model Innovation Strategy: Transformational Concepts and Tools for Entrepreneurial Leaders; John Wiley \& Sons: Hoboken, NJ, USA, 2020.

5. Zott, C.; Amit, R. Business model innovation: How to create value in a digital world. GfK Mark. Intell. Rev. 2017, 9, 18-23. [CrossRef]

6. Mingers, J.; Brocklesby, J. Multimethodology: Towards a Framework for Mixing Methodologies. Omega Int. J. Manag. Sci. 1997, 25, 489-509. [CrossRef]

7. Midgley, G. Systemic Intervention. Philosophy, Methodology, and Practice; Springer: New York, NY, USA, 2000.

8. Meadows, D.H. Thinking in Systems, A Primer; Chelsea Green Publishing: Chelsea, VT, USA, 2008.

9. Checkland, P.; Poulter, J. Soft Systems Methodology. In Systems Approaches to Making Change: A Practical Guide; Reynolds, M., Holwell, S., Eds.; Springer: London, UK, 2020; pp. 201-253.

10. Gharajedaghi, J. Systems Thinking: Managing Chaos and Complexity: A Platform for Designing Business Architecture, 3rd ed.; Elsevier: Amsterdam, The Netherlands, 2011.

11. Cabrera, D.; Cabrera, L. What Is Systems Thinking? In Learning, Design, and Technology; Spector, M., Lockee, B., Childress, M., Eds.; Springer: Cham, Switzerland, 2019.

12. Reynolds, M.; Holwell, S. (Eds.) Introducing Systems Approaches. In Systems Approaches to Making Change: A Practical Guide; Springer: London, UK, 2020; pp. 1-24.

13. Monat, J.P.; Gannon, T.F. What is systems thinking? A review of selected literature plus recommendations. Am. J. Syst. Sci. 2015, $4,11-26$.

14. Midgley, G.; Rajagopalan, R. Critical Systemms Thinking, Systemic Intervention, and Beyond. In Handbook of Systems Sciences; Metcalf, G.S., Ed.; Springer: Singapore, 2021; pp. 107-157.

15. Velu, C. A systems perspective on business model evolution: The case of an agricultural information service provider in India. Long Range Plan. 2017, 50, 603-620. [CrossRef]

16. Massa, L.; Gianluigi, V.; Tucci, C. Business models and complexity. J. Bus. Models 2018, 6, 59-71.

17. Cavallo, A.; Manotti, J.; Ghezzi, A.; Sedehi, H.; Rangone, A. Business Model Innovation for Sustainability: A System Dynamics Approach. In Proceedings of the 15th European Conference on Innovation and Entrepreneurship (ECIE 2020), Rome, Italy, 17-18 September 2020.

18. Monat, J.; Amissah, M.; Gannon, T. Practical Applications of Systems Thinking to Business. Systems 2020, 8, 14. [CrossRef]

19. Amit, R.; Zott, C. Value creation in e-business. Strateg. Manag. J. 2001, 22, 493-520. [CrossRef]

20. Zott, C.; Amit, R.; Massa, L. The business model: Recent developments and future research. J. Manag. 2011, 37, $1019-1042$.

21. Foss, N.J.; Saebi, T. Fifteen years of research on business model innovation: How far have we come, and where should we go? J. Manag. 2017, 43, 200-227. [CrossRef]

22. Massa, L.; Tucci, C.; Afuah, A. A Critical Assessment of Business Model Research. Acad. Manag. Ann. 2017, 11, 73-104. [CrossRef]

23. Nielsen, C.; Lund, M.; Montemari, M.; Paolone, F.; Massaro, M.; Dumay, J. Business Models: A Research Overview; Routledge: London, UK, 2018.

24. Andreini, D.; Bettinelli, C.; Foss, N.J.; Mismetti, M. Business model innovation: A review of the process-based literature. J. Manag. Gov. 2021, 25, 1-33. [CrossRef]

25. Martins, L.L.; Rindova, V.P.; Greenbaum, B.E. Unlocking the hidden value of concepts: A cognitive approach to business model innovation. Strateg. Entrep. J. 2015, 9, 99-117. [CrossRef]

26. Prahalad, C.K.; Bettis, R.A. The dominant logic: A new linkage between diversity and performance. Strateg. Manag. J. 1986, 7 , 485-501. [CrossRef]

27. Chesbrough, H. Business model innovation: Opportunities and barriers. Long Range Plan. 2010, 43, 354-363. [CrossRef]

28. Zott, C.; Amit, R. Business model design: An activity system perspective. Long Range Plan. 2010, 43, 216-226. [CrossRef] 
29. Foss, N.J.; Saebi, T. Business models and business model innovation. Between wicked and paradigmatic problems. Long Range Plan. 2018, 51, 9-21. [CrossRef]

30. Porter, M.E. Competitive Advantage: Creating and Sustaining Superior Performance; Free Press: New York, NY, USA, 1985.

31. Barney, J. Firm resources and sustained competitive advantage. J. Manag. 1991, 17, 99-120. [CrossRef]

32. Schumpeter, J.A. The Theory of Economic Development: An Inquiry into Profits, Capital, Credit, Interest, and the Business Cycle; Harvard University Press: Cambridge, MA, USA, 1934.

33. Gulati, R.; Nohria, N.; Zaheer, A. Strategic networks. Strateg. Manag. J. 2000, 21, 203-215. [CrossRef]

34. Williamson, O.E. Markets and Hierarchies, Analysis and Antitrust Implications: A Study in the Economics of Internal Organization; Free Press: New York, NY, USA, 1975.

35. Demil, B.; Lecocq, X. Business model evolution: In search of dynamic consistency. Long Range Plan. 2010, 43, 227-246. [CrossRef]

36. Chesbrough, H.; Rosenbloom, R.S. The role of the business model in capturing value from innovation: Evidence from Xerox corporation's technology spin-off companies. Ind. Corp. Chang. 2002, 11, 529-555. [CrossRef]

37. Snihur, Y.; Zott, C. The genesis and metamorphosis of novelty imprints: How business model innovation emerges in young ventures. Acad. Manag. J. 2020, 63, 554-583. [CrossRef]

38. Yoo, Y.; Henfridsson, O.; Lyytinen, K. Research Commentary-The New Organizing Logic of Digital Innovation: An Agenda for Information Systems Research. Inf. Syst. Res. 2010, 21, 724-735. [CrossRef]

39. Hukal, P.; Henfridsson, O. Digital Innovation-A definition and integrated perspective. In The Routledge Companion to Management Information Systems, 1st ed.; Routledge: London, UK, 2017; pp. 360-369.

40. Lyytinen, K. Innovation logics in the digital era: A systemic review of the emerging digital innovation regime. Innovation 2021, 1-22. [CrossRef]

41. Nambisan, S.; Lyytinen, K.; Majchrzak, A.; Song, M. Digital innovation management: Reinventing innovation management research in a digital world. MIS Q. 2017, 41, 223-238. [CrossRef]

42. Svahn, F.; Mathiassen, L.; Lindgren, R. Embracing Digital Innovation in Incumbent Firms: How Volvo Cars Managed Competing Concerns. MIS Q. 2017, 41, 239-253. [CrossRef]

43. Berglund, H.; Sandström, C. Business model innovation from an open systems perspective: Structural challenges and managerial solutions. Int. J. Prod. Dev. 2013, 18, 274-285. [CrossRef]

44. Halecker, B.; Hartmann, M. Contribution of systems thinking to business model research and business model innovation. Int. J. Technol. Intell. Plan. 2013, 9, 251-270. [CrossRef]

45. Pereira, S.G.M.; dos Santos Medina, F.A.; Gonçalves, R.F.; da Silva, M.T. System thinking and business model canvas for collaborative business models design. In Proceedings of the IFIP International Conference on Advances in Production Management Systems, Iguassu Falls, Brazil, 3-7 September 2016; pp. 461-468.

46. Bertalanffy, L.V. General Systems Theory; Penguin University Books: London, UK, 1968.

47. Hindle, G.A.; Vidgen, R. Developing a business analytics methodology: A case study in the foodbank sector. Eur. J. Oper. Res. 2018, 268, 836-851. [CrossRef]

48. Osterwalder, A.; Pigneur, Y. Business Model Generation: A Handbook for Visionaries, Game Changers, and Challengers; John Wiley \& Sons: Hoboken, NJ, USA, 2010.

49. Checkland, P. Systems Thinking, Systems Practice: Includes a 30 Year Retrospective; John Wiley \& Sons: Chichester, UK, 1999.

50. 8 Things We Can Learn about Systems Thinking from the Coronavirus Crisis. Available online: https://blog.cabreraresearch.org/ 8-things-we-can-learn-about-systems (accessed on 17 September 2021).

51. Kaplan, S. The Business Model Innovation Factory: How to Stay Relevant when the World Is Changing; John Wiley \& Sons: Hoboken, NJ, USA, 2012.

52. Fagerjord, A.; Kueng, L. Mapping the core actors and flows in streaming video services: What Netflix can tell us about these new media networks. J. Media Bus. Stud. 2019, 16, 166-181. [CrossRef]

53. Hadida, A.L.; Lampel, J.; Walls, W.D.; Joshi, A. Hollywood studio filmmaking in the age of Netflix: A tale of two institutional logics. J. Cult. Econ. 2020, 45, 213-238. [CrossRef]

54. Mier, J.; Kohli, A.K. Netflix: Reinvention across multiple time periods, reflections and directions for future research. AMS Rev. 2021, 11, 194-205. [CrossRef]

55. How to Download Titles to Watch Offline. Available online: https://help.netflix.com/en/node/54816 (accessed on 1 October 2021).

56. Jaworski, B.J. Netflix: Reinvention across multiple time periods. AMS Rev. 2021, 11, 180-193. [CrossRef]

57. Mingers, J. Multi-Paradigm Methodology. In Multimethodology: Theory and Practice of Combining Management Science Methodologies; Mingers, J., Gill, A., Eds.; Wiley: Chichester, UK, 1997; pp. 1-20.

58. Jackson, M.C. Critical Systems Thinking and the Management of Complexity; Wiley: Chichester, UK, 2019. 